\title{
Anti-Cancer Effects of Paris Polyphylla Ethanol Extract by Inducing Cancer Cell Apoptosis and Cycle Arrest in Prostate Cancer Cells
}

\author{
Denglu Zhanga,d Kailin Li ${ }^{\mathrm{c}, \mathrm{d}} \quad$ Chao Sun ${ }^{c, d}$ Guangshang Cao ${ }^{\mathrm{a}} \quad$ Yuanfu Qi \\ Zhaomin Lin ${ }^{c}$ Yanxia Guo ${ }^{c}$ Zhiyong Liu ${ }^{a}$ Yuan Chen ${ }^{c, d}$ Jiaxin Liu ${ }^{a}$ \\ Guanghui Cheng c,d Peng Wang ${ }^{c, d} \quad$ Lu Zhang $^{c}$ Jianye Zhang ${ }^{b}$ \\ Jiliang Wen $^{\mathrm{b}} \quad$ Dawei Xu ${ }^{\mathrm{e}, f} \quad$ Feng Kong ${ }^{\mathrm{c}, \mathrm{d}, f}$ Shengtian Zhao ${ }^{\mathrm{a}, \mathrm{b}, \mathrm{d}, \mathrm{f}}$
}

aThe Affiliated Hospital of Shandong University of Traditional Chinese Medicine; Department of bUrology and 'Central Research Laboratory, The Second Hospital of Shandong University; ${ }^{d K e y ~ L a b o r a t o r y ~ f o r ~ K i d n e y ~ R e g e n e r a t i o n ~ o f ~ S h a n d o n g ~ P r o v i n c e, ~ J i n a n, ~ C h i n a ; ~}$

eDepartment of Medicine, Division of Hematology and Centre for Molecular Medicine, Karolinska University Hospital Solna and Karolinska Institutet, Stockholm, Sweden; 'Shandong University-Karolinska Institutet Collaborative Laboratory for Cancer Research, Jinan, China

\section{Key Words}

Paris polyphylla • Prostate cancer • Cell appotosis •

Cycle arrest

\begin{abstract}
Objective: To evaluate the potential anti-prostate cancer effects of Paris polyphylla ethanol extract (PPEE) and its underlying mechanisms. Materials and Methods: The anti-proliferation activity of PPEE was tested on PC3 and DU145 cells using Cell Counting Kit-8 assay. The pro-apoptotic and cell cycle arrest effects of PPEE were confirmed by flow cytometry. Apoptosis of prostate cancer cells was induced by PPEE through endogenous and exogenous pathways. A mouse xenograft model was used to examine its anti-prostate cancer effects in vivo. Results: We found that the IC50 of PPEE on PC3 cells was $3.98 \mu \mathrm{g} / \mathrm{ml}$ and the IC50 of PPEE on DU145 cells was $8 \mu \mathrm{g} / \mathrm{ml}$. PPEE induced prostate cancer cell apoptosis in a concentration dependent manner, through endogenous and exogenous pathways. PPEE induced PC3 cell cycle arrest in G0/G1 and G2/M phases, while in DU145cell it induced cell arrest in the G0/G1 phase. PPEE inhibited the growth of prostate cancer cells in vivo. Conclusion: PPEE could inhibit
\end{abstract}

prostate cancer growth in vitro and in vivo, induce apoptosis of prostate cancer cells, and cause cell cycle arrest, which laid the foundation for further research on the anti-tumor mechanism of PPEE.

Copyright $\odot 2017$ S. Karger AG, Basel

\section{Introduction}

Prostate cancer is one of the most commonly diagnosed malignancies in men $[1,2]$. Despite advances in early diagnosis and treatment, the morbidity remains high. The survival rates remain poor especially for castration-resistant prostate cancer (CRPC) patients, with cancer usually recurring within 2-3 years [3, 4]. Although the androgen-related signaling axis plays an important role in the tumorigenesis and progression of CRPC, other pathways may also significantly contribute to castration-resistance. At present, there is limited treatment strategy for CRPC $[5,6]$. Therefore, understanding the mechanisms of CRPC and searching for novel strategies to enhance the therapeutic efficacy are urgently needed.

\section{KARGER}

Fax +4161306 1234

E-Mail karger@karger.com

www.karger.com
(C) 2017 S. Karger AG, Basel

Accessible online at: www.karger.com/cur
Dawei Xu

Key Laboratory for Kidney Regeneration of Shandong Province Beiyuan Street No. 247 CN-250033 Jinan (China) E-Mail dawei.xu@ki.se
Feng Kong

The Second Hospital of Shan-

dong University

Beiyuan Street No. 247

CN-250033 Jinan (China)

E-Mail kongfeng@sdu.edu.cn
Shengtian Zhao

The Affiliated Hospital of Shandong University of Traditional

Chinese Medicine

CN-250011 Jinan (China)

E-Mail zhaoshengtian@sdu.edu.cn 


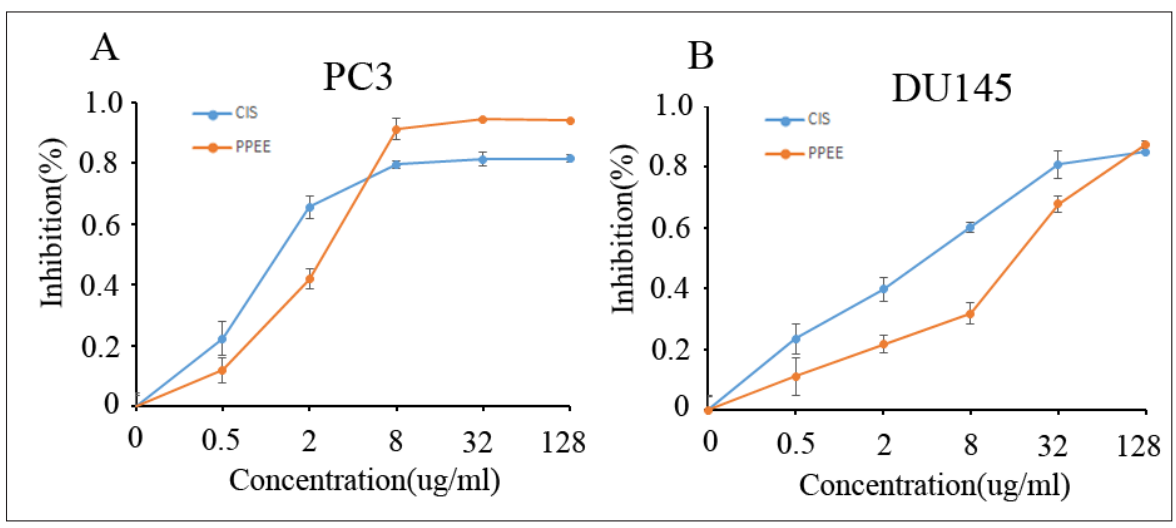

Fig. 1. The inhibition of PPEE on prostate cancer cell viability by CCK8 assay. A The inhibition of PPEE on PC3 cell viability, cisplatin as a control; B The inhibition of PPEE on DU145 cell viability, cisplatin as a control.

Traditional Chinese medicines (TCMs) have a long history of cancer treatment in China. With increasing evidence from preclinical and clinical studies, it is accepted that TCM is an important complementary and alternative therapy because of its valid anti-tumor effect, lower price, and toxicity [7]. Hence, there is an urgent need to develop safe and effective anti-prostate cancer drugs derived from Chinese herbs.

Paris polyphylla, a traditional antipyretic-detoxicate Chinese medicinal herb, has been extensively applied in cancer treatments for nearly 2,000 years. Paris polyphylla has been reported to possess anti-cancer properties in various cancer types [8-11]. However, there is little research on Paris polyphylla's effect on prostate cancer. In this study, we evaluated the potential anti-prostate cancer effects of Paris polyphylla ethanol extract (PPEE) in in vitro and in vivo.

\section{Materials and Methods}

\section{Cell Culture}

PC 3 cells (The Cell Bank of Chinese Academy of Sciences, Shanghai) were cultured in F12K medium (HyClone) supplemented with 10\% fetal bovine serum (Gibco), and DU145 Cells (The Cell Bank of Chinese Academy of Sciences, Shanghai) were cultured in RPMI 1640 medium (HyClone) supplemented with $10 \%$ fetal bovine serum (Gibco). Cells were maintained in a humidified incubator with $5 \% \mathrm{CO}_{2}$ at $37^{\circ} \mathrm{C}$.

\section{Preparation of Paris polyphylla Extract}

The raw herb Paris polyphylla Smith var. yunnanensis (Franch.) Hand.-Mazz., originating from China, was purchased from a supplier in Jinan and was identified by Prof. Chuanjiang $\mathrm{Ma}$ (from The Affiliated Hospital of Shandong University of Tra- ditional Chinese Medicine, Jinan, China). An authenticated herbal voucher specimen was deposited in The Affiliated Hospital of Shandong University of Traditional Chinese Medicine.

To prepare the ethanol extract, dried Paris polyphylla was extracted with $60 \%$ ethanol under reflux for 2 hours. The extract was filtered, and the extraction was repeated. Subsequently, the filtrates were combined, concentrated, and then water precipitated. The extract was refrigerated for 12 hours, then filtered, and the precipitation was dried into powder. The total saponins of Paris polyphylla ethanol extract were greater than $80 \%$ as determined by an ultraviolet-visible spectrophotometer at $406 \mathrm{~nm}$ with perchloric acid as the chromogenic reagent.

\section{Cell Viability Assay}

Cell viability was assessed using the Cell Counting Kit-8 assay (CCK8) according to the manufacturer's protocol (Dojindo, Shanghai). Cells were seeded at $2 \times 10^{3}$ cells/well in 96-well plates and incubated with gradient concentrations of PPEE at $37^{\circ} \mathrm{C}$ for 48 hours in a humidified chamber containing 5\% CO. CCK8 solution $(10 \mu \mathrm{l})$ was added to each well, and the plates were incubated for 1 hour at $37^{\circ} \mathrm{C}$. The absorbance of cells at $450 \mathrm{~nm}$ (OD450) was measured in a microplate reader (Thermo Scientific, USA).

\section{Cell Apoptosis Detection}

Cells were harvested, washed in ice-cold PBS, and resuspended in $200 \mu \mathrm{l}$ of binding buffer before being incubated in $5 \mu \mathrm{L}$ of annexin-V-FITC (BD Biosciences, San Diego, CA, USA) solution and $5 \mu$ of propidium iodide (PI) at room temperature for 15 minutes in the dark. Subsequently, $200 \mu$ of a binding buffer was added. Cells were analyzed through flow cytometry. Untreated cells were used as double stained controls.

\section{Cell Cycle Analysis}

The cell cycle was assessed using the GENMED Universal periodic flow cytometry kit according to the manufacturer's protocol (Genmed Scientifics Inc, USA). Cells were seeded at $1.2 \times 10^{5}$ cells/well in 6-well plates and incubated with gradient concentrations of PPEE at $37^{\circ} \mathrm{C}$ for 48 hours in a humidified chamber containing $5 \% \mathrm{CO}_{2}$. 


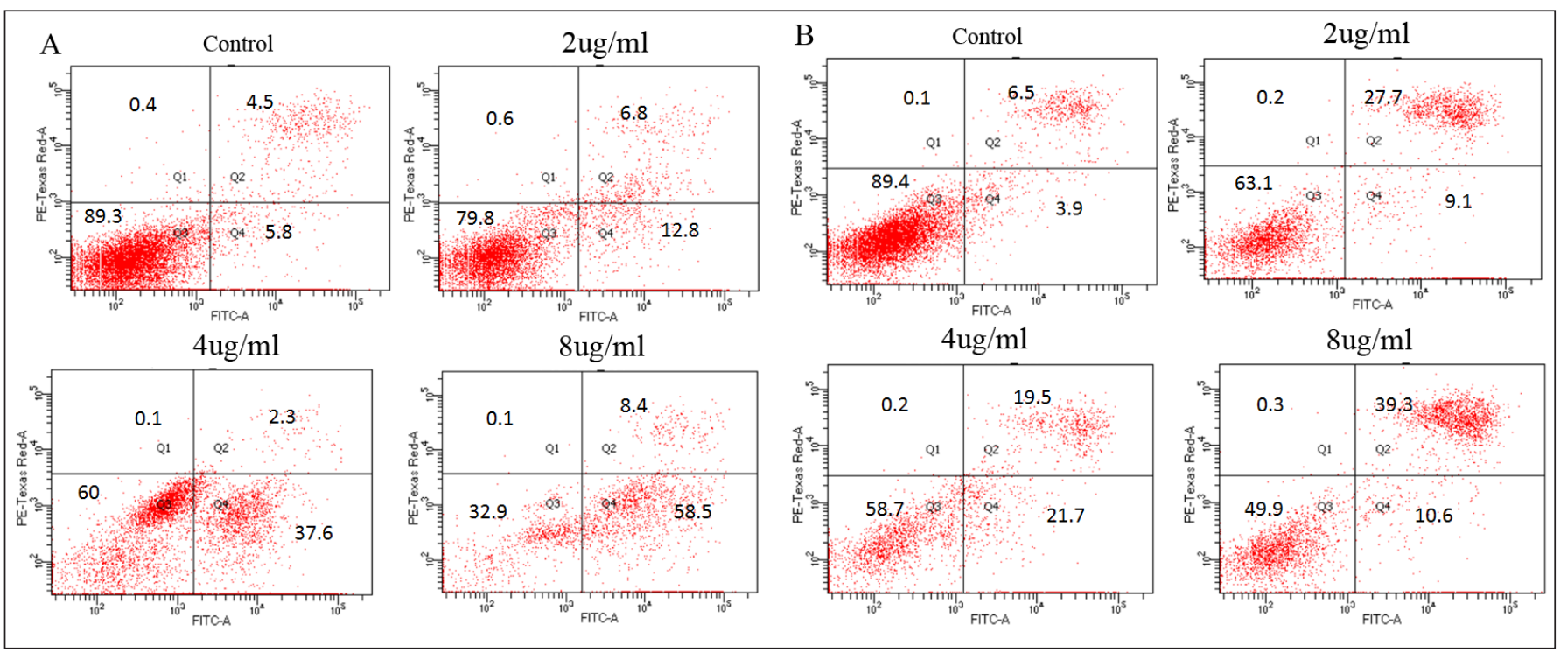

Fig. 2. Detection of apoptosis in prostate cancer cells treated by gradient concentrations of PPEE. A PPEE induced apoptosis of PC3 cells; B PPEE induced apoptosis of DU145 cells.

\section{Western Blotting}

Protein sample preparation and Western blotting were performed as previously described [12]. Blots were incubated with primary antibodies against $\beta$-actin, PARP1, Bcl2, Bax, Caspase-8, and Caspase-3 (Cell Signaling Technology Company) overnight at $4{ }^{\circ} \mathrm{C}$, followed by appropriate peroxidase-conjugated secondary antibodies. $\beta$-actin served as an internal control. Visualization of the immunocomplexes was done by an enhanced chemiluminescence detection system (Millipore) followed by exposure to X-ray films.

\section{Animal Experiments}

The anti-prostate cancer effect of PPEE in vivo was evaluated in a PC3 xenograft mouse model. BALB/c nude mice were grafted with $2 \times 10^{6} \mathrm{PC} 3$ cells via injection into the right flank. After the development of a palpable tumor $(2 \times 2 \mathrm{~mm}$ minimum 14 days post-engraftment), animals were pair-matched by tumor size and treated by intragastric administration of $0.9 \%$ sodium chloride, or PPEE $(50 \mathrm{mg} / \mathrm{kg}$ and $100 \mathrm{mg} / \mathrm{kg}$ ) or 5 -fluorouracil (5-FU) every day. After a 21-day treatment, tumor tissues were collected for hematoxylin and eosin staining and immunohistochemical analysis. All animal experiments were approved by the Ethics Committee of The Affiliated Hospital to Shandong University of Traditional Chinese Medicine and accordingly conducted.

\section{Histopathological Examination}

For the histopathological examination, portions of PC3 xenografts were fixed in $10 \%$ formalin. After proper dehydration, the tumor tissues were embedded in paraffin wax. Sections $(5 \mu \mathrm{m})$ were prepared and stained with hematoxylin and eosin.

\section{Statistical Analysis}

A paired Student's $t$ test was used for analysis of statistical significance between the control and treated groups. The compar- ative data were expressed as the mean \pm SD of at least three independent experiments. Tumor weight and the rate of Ki67 positive cells were measured and presented as mean \pm SEM and compared by means of one-way analysis of variance (ANOVA). p $<0.05$ was considered statistically significant.

\section{Results}

\section{PPEE Inhibits the Growth of Prostate Cancer Cells in vitro}

To study the effect of PPEE on the growth of human prostate cancer cells, PC3 and DU145 cells were treated with various concentrations $(0,0.5,2,8,32$, and $128 \mu \mathrm{g} / \mathrm{ml}$ ) of PPEE for 48 hours, and cell viability was determined using CCK8 assay. In this study, we chose cisplatin as a positive control. We found that the IC50 of PPEE on PC3 cells was $3.98 \mu \mathrm{g} / \mathrm{ml}$ and the IC50 of PPEE on DU145 cells was $8 \mu \mathrm{g} / \mathrm{ml}$ (fig.1). Experimental results proved that PPEE had a weaker anti-cancer effect on prostate cancer cell viability than cisplatin.

\section{PPEE Induces Apoptosis in Prostate Cancer Cells}

Having observed significant decreases of the viability in prostate cell lines exposed to PPEE, the induction of apoptosis by PPEE was assessed. As shown in figure 2A, the gradient concentration of PPEE induced apoptosis in PC3 cells, while cell necrosis was rarely seen. The proportion of apoptotic cells increased with increased drug 


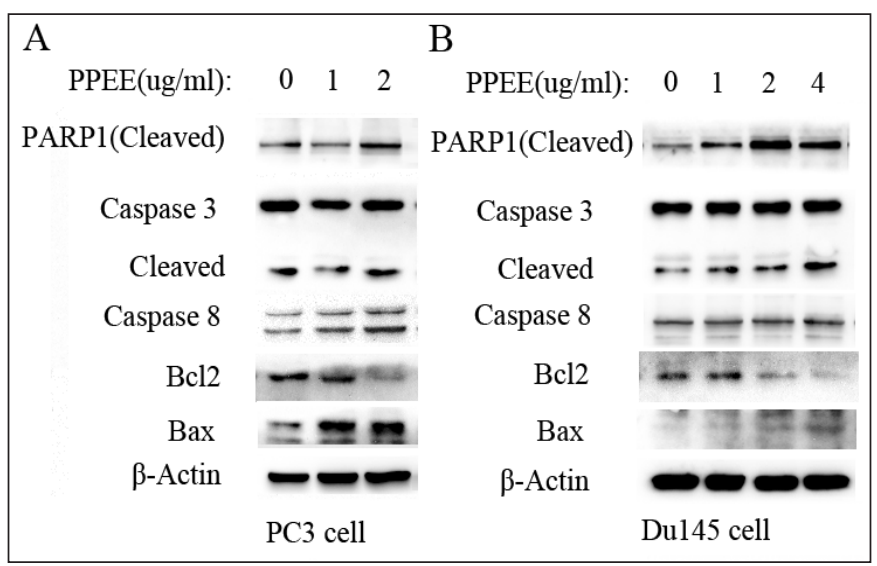

Fig. 3. Expression of molecular markers of apoptosis in prostate cancer cells treated by gradient concentrations of PPEE. A Expression of molecular markers of apoptosis in PC3 cells; B Expression of molecular markers of apoptosis in DU145 cells.

concentrations. Similar results were found in the DU145 cells (fig. 2B). The result confirmed that PPEE could induce apoptosis in prostate cancer cells in a dose-dependent manner.

In order to study the mechanism of apoptosis induced by PPEE in prostate cancer cells, we first detected expression of PARP1 which is a molecular marker of apoptosis. As the drug concentration increased, expression of cleaved PARP1 was enhanced in both PC3 and DU145 cells (fig. 3). We further examined the molecular markers of endogenous and exogenous apoptosis. The result showed that PPEE reduced expression of $\mathrm{Bcl} 2$, while it enhanced expression of Bax. Similar results were found in both PC3 and DU145 cells. Furthermore, as the drug concentration increased, expression of cleaved caspase- 8 was enhanced in PC3 cells, while expression of cleaved caspase-3 was enhanced in DU145cells. In summary, apoptosis of prostate cancer cells was induced by PPEE through endogenous and exogenous pathways.

\section{PPEE Causes Cell Cycle Arrest in Prostate Cancer Cells}

To examine whether PPEE inhibits cell proliferation via cell cycle arrest, we performed flow cytometry analysis to investigate cell cycle distribution after PPEE treatment. The result showed that a low concentration $(1 \mu \mathrm{g} /$ $\mathrm{ml}$ ) of PPEE had little effect on the prostate cancer cell cycle. When the drug concentration was 2 or $4 \mu \mathrm{g} / \mathrm{ml}$, the proportion of cell cycle arrest in the G0/G1 phase and

Paris Polyphylla Ethanol Extract Exerts Anti-Cancer Effects
G2/M phase remarkably increased (fig. 4A). However, DU145 cells were mainly arrested in the G0/G1 phase in the presence of higher concentrations of PPEE (fig. 4B).

\section{PPEE Inhibits the Growth of Prostate Cancer Cells} in vivo

In order to prove the effect of PPEE on prostate cancer in vivo, a prostate xenograft model was established. PC3 xenograft tumors were allowed to reach approximately $10 \mathrm{~mm}^{3} 2$ weeks post-implantation, at which point treatment of different doses of PPEE or 5-FU was initiated. As shown in figure $5 \mathrm{~A}$, treatment with PPEE induced an anti-tumor response in PC3 xenograft development in a dose-dependent manner in which the highest dose demonstrated an effect similar to that of 5-FU. On day 21 after completion of therapy, PPEE at $100 \mathrm{mg} / \mathrm{kg}$ resulted in a tumor volume of $333.01 \pm 34.77 \mathrm{~mm}^{3}$, which represents an inhibition rate of $51.05 \%$. Furthermore, PPEE at a dose of $50 \mathrm{mg} / \mathrm{kg}$ resulted in volumes of $450.51 \pm$ $34.77 \mathrm{~mm}^{3}$ at day 21 , representing inhibition rates of $38.78 \%$. Consistently, image of tumors excised from the mice after sacrificing at the end of treatment showed that PC3 xenograft tumors in the PPEE treatment group were obviously smaller than in the control group (fig. 6A and B). Tumor weights in 50 and $100 \mathrm{mg} / \mathrm{kg}$ were 65.50 and $49.84 \%$ of that in control group mice, respectively (fig. 6C). It is worth noting that PPEE treatment did not cause obvious body weight loss throughout the course of the therapy (fig. 5B). The result of histopathological examination showed that cell density of xenograft tumors in the PPEE treatment group was significantly lower than in the control group (fig 7A, 7B), which confirmed the in vivo anti-prostate cancer effects of PPEE.

\section{Discussion}

Although chemotherapy has been considered a historic milestone in the treatment of prostate cancer, resulting in considerable progress in the prognosis of prostate cancer patients, the overall survival rate has remained basically unimproved during the past decades [4]. Additionally, severe systemic toxicity of chemotherapeutic drugs has limited their application. Therefore, the search for novel therapeutic agents to improve the clinical outcome is highly desired. Antipyretic detoxicate is one of the predominant treatments for cancer in Chinese medicine [13-17]. As a kind of heat-clearing and detoxicating herb, rhizomes of Paris polyphylla were shown to exert potent anti-tumor effects and have been widely used in 


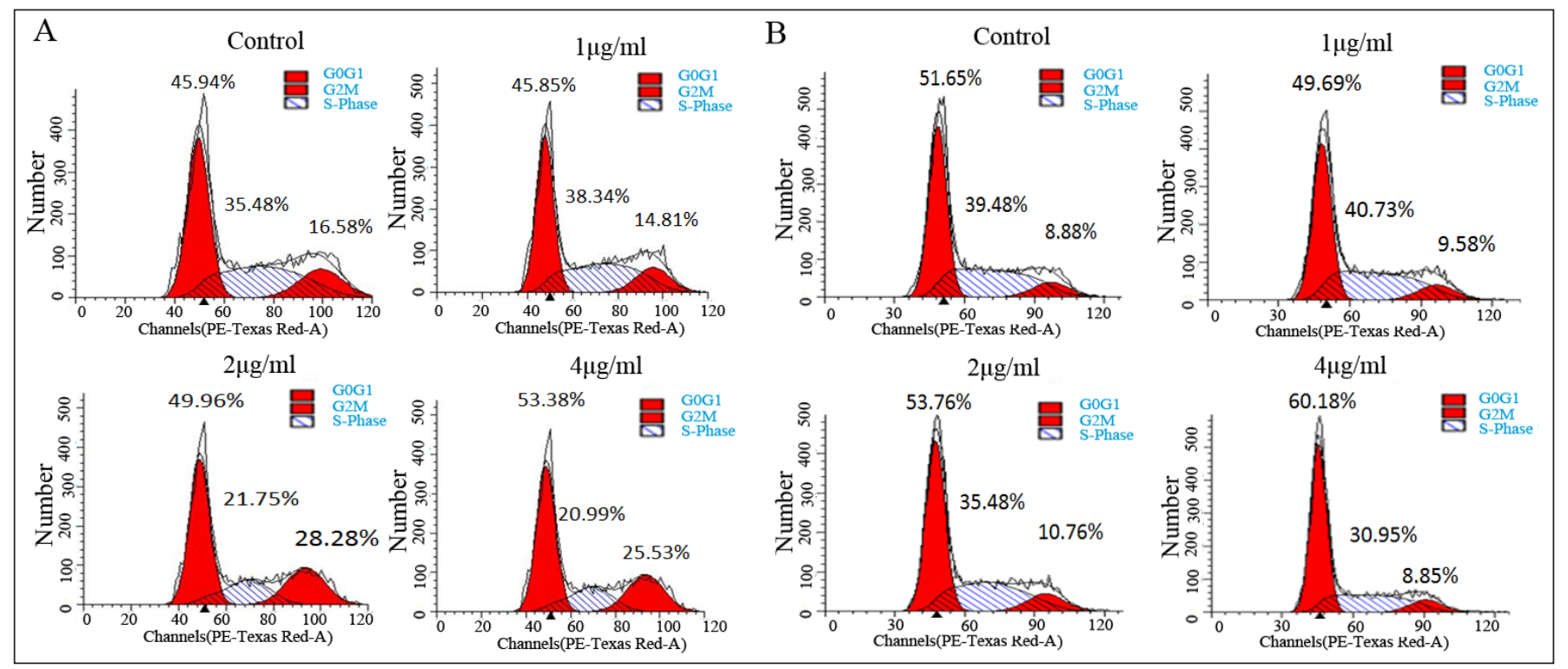

Fig. 4. PPEE caused cell cycle arrest in prostate cancer cells. A PPEE caused cell cycle arrest in the G0/G1 phase and G2/M phase in PC3 cells; B PPEE caused cell cycle arrest in the G0/G1 phase in DU145 cells.

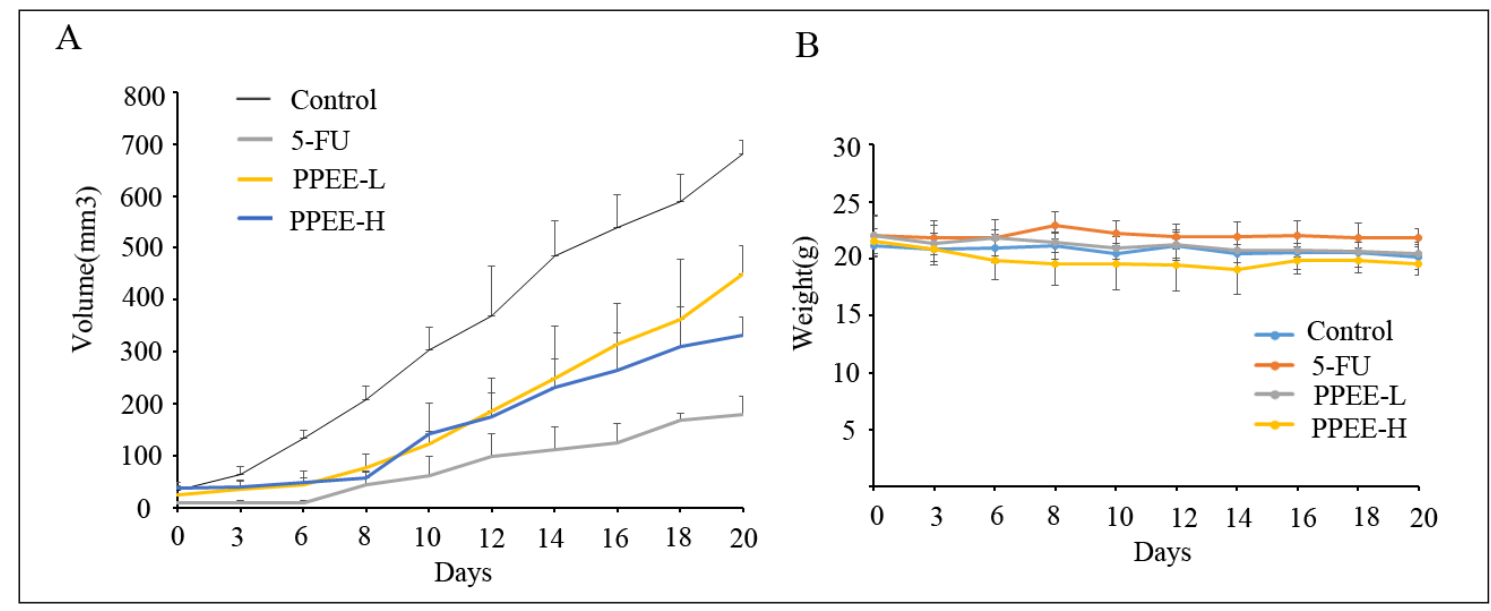

Fig. 5. PPEE inhibited the growth of prostate cancer cells in vivo. A The measurement of tumor volume at different time treated with drugs; B The measurement of body weight in mice at different time treated with drugs.

TCM in the treatment of cancer for approximately 2,000 years. Nonetheless, there is little research on Paris polyphylla's effects on prostate cancer. Our work presented here demonstrated that PPEE showed a profound inhibitory effect on human prostate cancer in vitro and in vivo by inducing apoptosis and cell cycle arrest with few toxic side effects to the host.
In the present study, the antiproliferative efficacy of PPEE on prostate cancer cells was measured by CCK8 assay. The results showed that PPEE inhibited cell viability in a concentration-dependent manner for PC3 and DU145 cells, with IC50 values of $4-10 \mu \mathrm{g} / \mathrm{ml}$. Similar results have been reported in osteosarcoma [8], colorectal [9] and breast cancers [10]. 


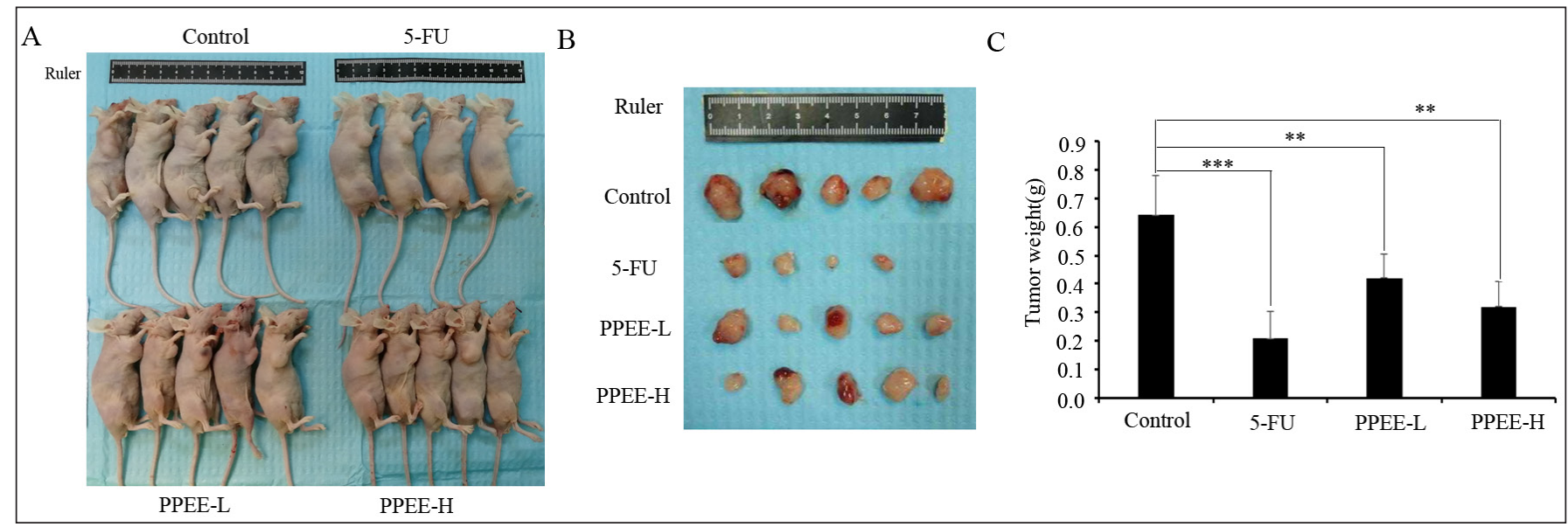

Fig. 6. The shape and weight of xenograft tumors in different treatment groups. A After 21 days of drug treatment, the mice were euthanized and photographed; B The photograph of xenograft tumors; C Tumor weight in different treatment groups.

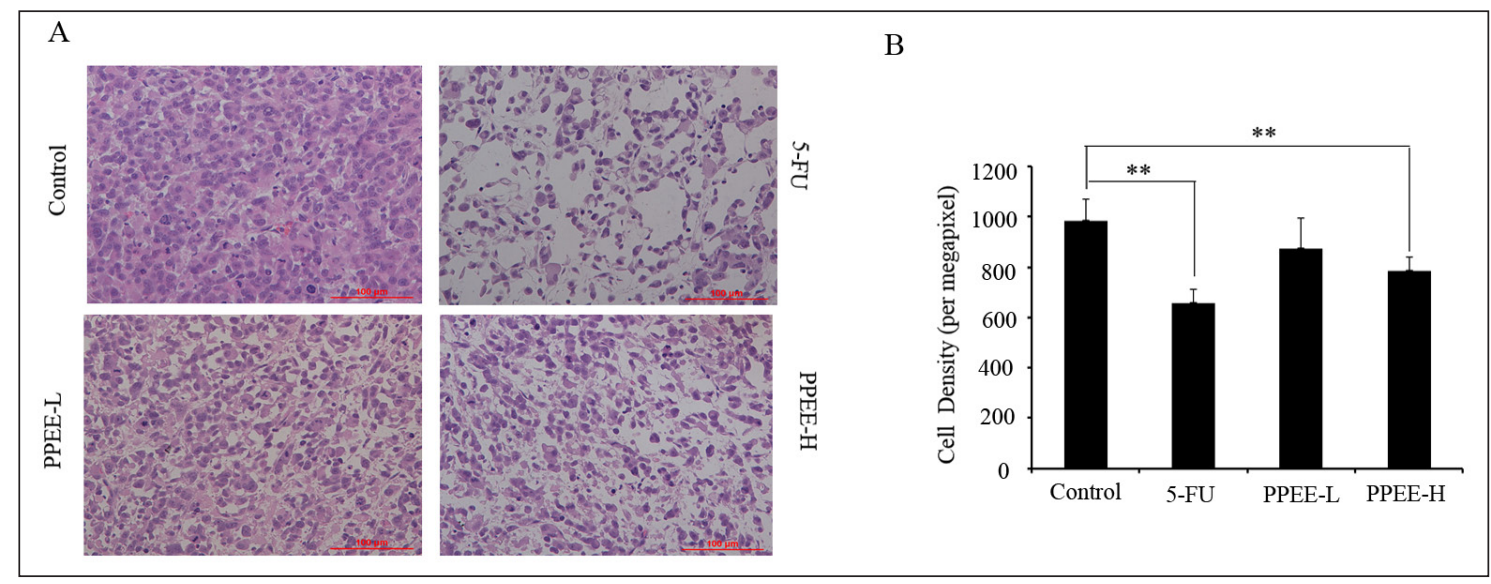

Fig. 7. Histopathological examination of different treatment groups. A HE staining morphology; B Tumor density analysis in different treatment groups.

Cell cycle deregulation is a hallmark of cancer cells. Targeting aberrant expression of proteins involved in critical cell cycle progression has turned out to be a productive strategy for cancer intervention [9]. FACS analyses showed that PPEE dose-dependently induced G2/M arrest of PC3 cells, while it induced G0/G1 arrest of both PC3 and DU145 cells.

Previous investigation suggested that induction of apoptosis is one of the main mechanisms underlying the anti-cancer effect of rhizomes of Paris polyphylla [8-10]. Here, we observed that PC 3 and DU145 cells underwent apoptosis after PPEE treatment as assessed by Annexin
V/PI assay. The percentages of early and late apoptotic PC3 and DU145 cells were both increased as the PPEE concentration increased. In order to study the mechanism of apoptosis induced by PPEE in prostate cancer cells, we first detected expression of PARP1 which is a molecular marker of apoptosis. As the drug concentration increased, expression of cleaved PARP1 was enhanced in both PC 3 and DU145 cells. We further examined the molecular markers of endogenous and exogenous apoptosis. The result revealed that apoptosis of prostate cancer cells was induced by PPEE through endogenous and exogenous pathways. 


\section{Conclusion}

This study demonstrated that PPEE exerts anti-prostate cancer effects by inducing apoptosis and cell cycle arrest. In the xenograft model of prostate cancer, PPEE also exhibited potent anti-tumor activity. These findings revealed that PPEE has potential therapeutic value in the treatment of prostate cancer.

\section{Acknowledgement}

This work was supported by the National Natural Science Foundation of China (81041065) and National Public Welfare Industry Research Project (201507002).

\section{References}

1 Siegel RL, Miller KD, Jemal A: Cancer statistics, 2018. CA Cancer J Clin 2018;68:730.

2 Gomella LG: Prostate cancer statistics: anything you want them to be. Can J Urol 2017; 24:8603-8604.

3 Nakano K, Komatsu K, Kubo T, Natsui S, Nukui A, Kurokawa S, Kobayashi M, Morita $\mathrm{T}$ : External validation of risk classification in patients with docetaxel-treated castration-resistant prostate cancer. BMC Urol 2014;14: 31.

4 O'Callaghan ME, Raymond E, Campbell J, Vincent AD, Beckmann K, Roder D, Evans S, McNeil J, Millar J, Zalcberg J, Borg M, Moretti K: Tools for predicting patient-reported outcomes in prostate cancer patients undergoing radical prostatectomy: a systematic review of prognostic accuracy and validity. Prostate Cancer Prostatic Dis 2017;20: 378-388.

5 Wei XX, Ko EC, Ryan CJ: Treatment strategies in low-volume metastatic castration-resistant prostate cancer. Curr Opin Urol 2017; 27:596-603.

6 Armstrong AJ: New treatment options in castration-resistant prostate cancer. J Natl Compr Canc Netw 2015;13(5 Suppl):690-693.
7 Ling CQ, Yue XQ, Ling C: Three advantages of using traditional Chinese medicine to prevent and treat tumor. J Integr Med 2014; 12(4):331-335.

8 Yao N, Ren K, Wang Y, Jin Q, Lu X, Lu Y, Jiang C, Zhang D, Lu J, Wang C, Huo J, Chen Y, Zhang J: Paris polyphylla suppresses proliferation and vasculogenic mimicry of human osteosarcoma cells and inhibits tumor growth in vivo. Am J Chin Med 2017;43: 575-598.

9 Yu S, Wang L, Cao Z, Gong D, Liang Q, Chen H, Fu H, Wang W, Tang X, Xie Z, He Y, Peng C, Li Y: Anticancer effect of Polyphyllin I in colorectal cancer cells through ROS-dependent autophagy and G2/M arrest mechanisms. Nat Prod Res 2017;31:1-4.

10 Li GB, Fu RQ, Shen HM, Zhou J, Hu XY, Liu YX, Li YN, Zhang HW, Liu X, Zhang YH, Huang C, Zhang R, Gao N: Polyphyllin I induces mitophagic and apoptotic cell death in human breast cancer cells by increasing mitochondrial PINK1 levels. Oncotarget 2017; 8:10359-10374.

11 Jing S, Wang Y, Li X, Man S, Gao W: Chemical constituents and antitumor activity from Paris polyphylla Smith var. yunnanensis. Nat Prod Res 2017;31:660-666.
12 Yuan H, Gong A, Young CY: Involvement of transcription factor $\mathrm{Sp} 1$ in quercetin-mediated inhibitory effect on the androgenreceptor in human prostate cancer cells. 2005;26: 793-801.

13 Kuo YT, Liao HH, Chiang JH, Wu MY, Chen BC, Chang CM, Yeh MH, Chang TT, Sun MF, Yeh CC, Yen HR: Complementary Chinese herbal medicine therapy improves survival of patients with pancreatic cancer in Taiwan: a nationwide population-based cohort study. Integr Cancer Ther 2017:153473541772222.

14 Zhang L, Ren B, Zhang J, Liu L, Liu J, Jiang G, Li M, Ding Y, Li W: Anti-tumor effect of Scutellaria barbata D. Don extracts on ovarian cancer and its phytochemicals characterisation. J Ethnopharmacol 2017;206:184-192.

15 Huang M, Xin W: Matrine inhibiting pancreatic cells epithelial-mesenchymal transition and invasion through ROS/NF-KB/MMPs pathway. Life Sci 2018;192:55-61.

16 Zhu H, Zhao H, Zhang L, Xu J, Zhu C, Zhao H, Lv G: Dandelion root extract suppressed gastric cancer cells proliferation and migration through targeting IncRNA-CCAT1. Biomed Pharmacother 2017;93:1010-1017.

17 Lee SE, Lim C, Ahn SC, Cho S: A study of the anti-cancer effects of the hexane fraction of the methanol extract of Forsythiae Fructus. Pharmacogn Mag 2017;13:719-724. 